\title{
DYNAMICS of the VASCULAR SYSTEM
}

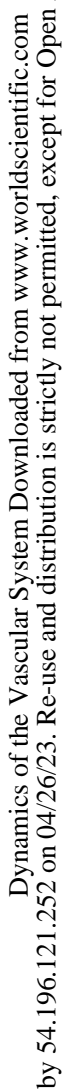




\section{SERIES ON BIOENGINEERING AND BIOMEDICAL ENGINEERING}

Series Editor: John K-J Li (Department of Biomedical Engineering, Rutgers University, USA)

Vol. 1: Dynamics of the Vascular System

by John K-J Li (Department of Biomedical Engineering, Rutgers University, USA)

VVol. 2: Neuroprosthetics

Theory and Practice

eds. Kenneth W Horch and Gurpreet S Dhillon (Department of Bioengineering, University of Utah, USA)

Cerebral Hemodynamics \& Metabolism Using Magnetic Resonance Imaging \& Spectroscopy

by Weili Lin (Department of Radiology, University of North Carolina, USA),

Chung Y Hsu and Williams Power (Department of Neurology, Washington University School of Medicine, USA) 
Series on Bioengineering \& Biomedical Engineering - Vol. I

\section{DYNAMICS of the VASCULAR SYSTEM}

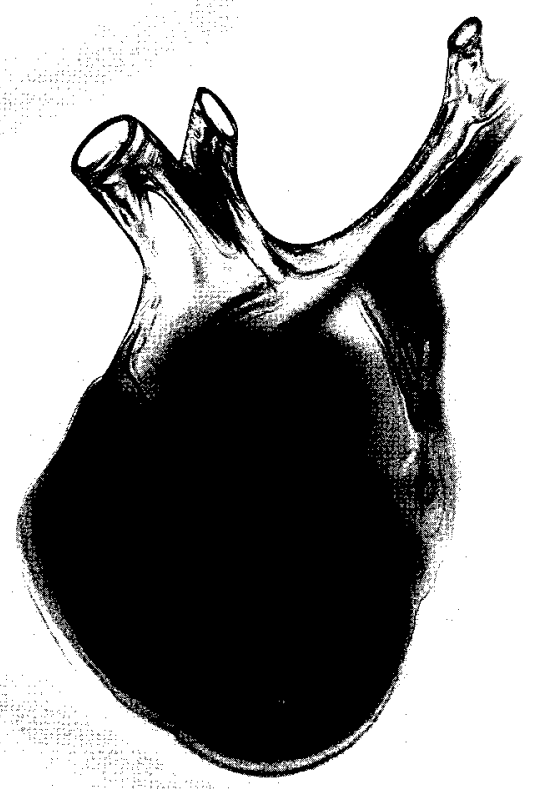

\section{John K-J Li}

Rutgers University, USA 
Published by

World Scientific Publishing Co. Pte. Ltd.

5 Toh Tuck Link, Singapore 596224

USA office: Suite 202, 1060 Main Street, River Edge, NJ 07661

UK office: 57 Shelton Street, Covent Garden, London WC2H 9HE

\section{British Library Cataloguing-in-Publication Data}

A catalogue record for this book is available from the British Library.

\section{DYNAMICS OF VASCULAR SYSTEM \\ Series on Bioengineering \& Biomedical Engineering - Vol. 1}

Copyright (C) 2004 by World Scientific Publishing Co. Pte. Ltd.

All rights reserved. This book, or parts thereof, may not be reproduced in any form or by any means, electronic or mechanical, including photocopying, recording or any information storage and retrieval system now known or to be invented, without written permission from the Publisher.

For photocopying of material in this volume, please pay a copying fee through the Copyright Clearance Center, Inc., 222 Rosewood Drive, Danvers, MA 01923, USA. In this case permission to photocopy is not required from the publisher.

ISBN 981-02-4907-1 


\section{Author Biography}

John K-J. Li received his Ph.D. in bioengineering in 1978 from the ह Presbyterian-University of Pennsylvania Medical Center from 1977잉 1979 prior to joining Rutgers University where he is currently a ×Professor II (distinguished) of Biomedical Engineering. He has been a Director of Joint Graduate Program of Rutgers and UMDNJ-Robert Wood Johnson Medical School and has supervised more than 60 Ph.D. a.s. theses projects. Dr. Li is a Fellow of the American Institute for Medical and Biological Engineering, the American College of Cordiology and the American College of Angiology. He is a recipient of IEEE Millennium Medal award and of research grants from the National Institutes of Health, the National Science Foundation, DOD and the American Heart Association on cardiovascular function, computer modeling, controlled drug delivery (with U.S. patents) and biomedical F sensors. He has served as a member of NIH special study sections, a 作 乡 Editor-in-chief of Cardiovascular Engineering: an International Journal 공 and has been an Associate Editor of IEEE Transactions on Biomedical Engineering and a number of other biomedical engineering journals. Dr. Li is a frequently invited speaker and scientific session chair on , cardiovascular dynamics, biomedical instrumentation and their clinical $\underset{\mathrm{C}}{\mathrm{C}}$ applications. He has more than 350 publications and Dynamics of the $\Xi$ Vascular System is his fifth book. Dr. Li is the Editor of World Scientific Bioengineering and Biomedical Engineering Book Series. 
This page intentionally left blank 


\section{Preface}

This book is the first volume of the Bioengineering and Biomedical g Engineering Book Series. As the Series Editor, and to set a good example, I have taken the task of writing yet another book on the ơ gardiovascular system.

作 my first book published some fifteen years ago, to distinctly different regimes of the microcirculation and the venous system, as well as the gassisted circulation.

The vascular system is indeed so vast, that a binocular vision is often Eneeded to unravel the mystery of the many concurrent interactions Eoccurring at different sites of the vascular tree. This becomes more 耐challenging with the imposition of studying its dynamic phenomena. "The Dynamics of the Vascular System" is written employing Imathematical techniques to formulate the physical principles involved in of the structural and functional correlates of the underlying physiology. The o intriguing control and geometric perspectives are also included wherever Jispossible. The book also serves as a companion text to "The Arterial JCirculation: Physical Principles and Clinical Applications".

Selected topics and references are provided, so that I and the readers तुare not overwhelmed by the otherwise exhaustive presentations of the Imany observed phenomena and the subsequent diverse interpretations of their origins and mechanisms.

I hope professionals and students in the field of bioengineering and biomedical engineering, biomathematics, biophysics, cardiovascular physiology and medicine will find this book a relevant source of 
reference. Much of the work is the culmination of my three decades of learning, experimenting and investigation. I am aware that there are other works of notable items and newer advances which I have not yet included in this book. I will continue to learn more of them. Finally, I like to thank those who have contributed to the completion of this book, especially Dr. Ying Zhu.

John $K-J$. Li New Jersey 


\section{Contents}

Preface vii

1. Historical Backgrounds and Book Contents

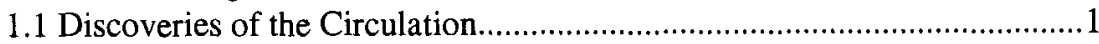

1.2 Importance of the Vascular System ......................................................

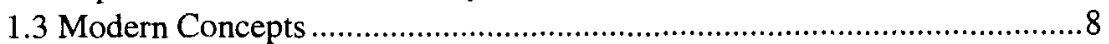

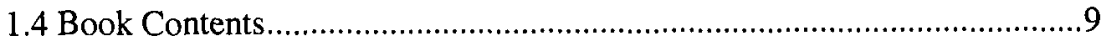

2. Vascular Biology, Structure and Function

2.1 Anatomical Organization of the Vasculature ..........................................14

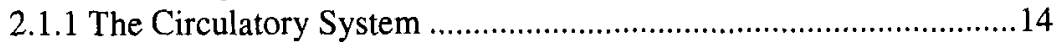

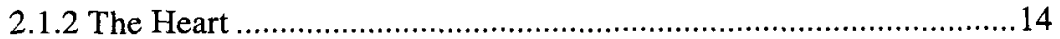

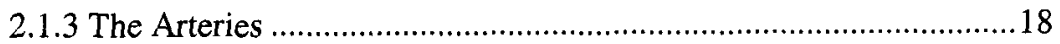

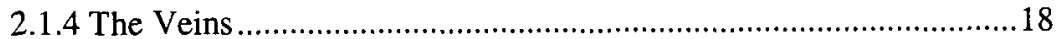

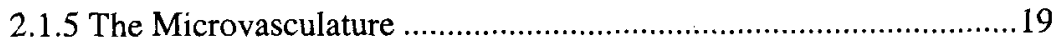

2.2 Mechanical Properties of Blood Vessels................................................20

2.2.1 Some Geometric Aspects of Blood Vessels ...................................20

2.2.2 Vascular Stiffness and Elastic Properties........................................25

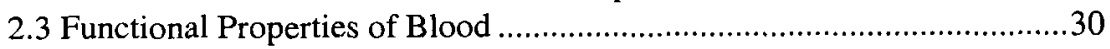

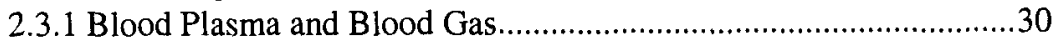

2.3.2 Oxygen Saturation Curves and Hemoglobin....................................31

2.3.3 Red Blood Cells, Hematocrit and Blood Volume ............................33

2.4 Control Aspects of the Vascular System...................................................35

2.4.1 Control of the Central Cardiovascular System.................................36

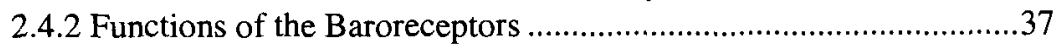

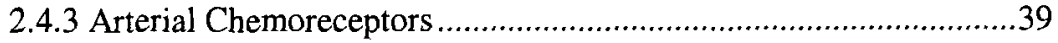

3. Physical Concepts and Basic Fluid Mechanics

3.1 Basic Mechanics and Dimensional Analysis ..........................................41

3.1.1 Mass, Length and Time System and the Pi-Theorem of Buckingham 


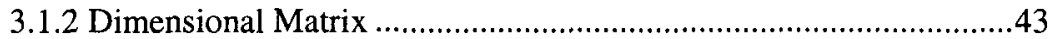

3.1.3 Dynamic Similitude in Vascular Biology .....................................44

3.1.4 Elastic and Viscoelastic Properties of Blood Vessels .......................46

3.2 Frequency Domain and Fourier Analysis ..............................................54

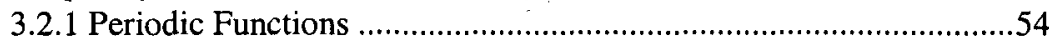

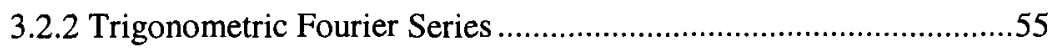

3.2.3 Complex Form of Fourier Series....................................................58

3.2.4 Other Aspects of Frequency Domain Analysis .................................60

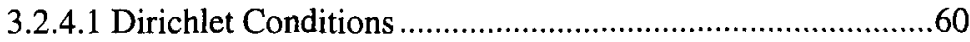

3.2.4.2 Line Spectrum and Nyquist Criterion .................................61

3.2.4.3 Correlation, Coherence and Power Spectrum ......................61

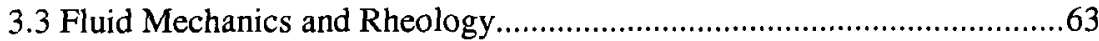

3.3.1 Steady Flow and Poiseuille Equation...............................................63

3.3.2 Bernoulli's Equation and Narrowing Vessel Lumen .......................67

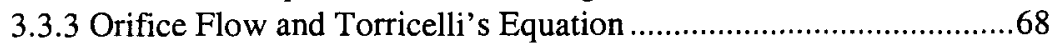

3.3.4 The Gorlin Equation .................................................................69

3.3.5 Flow and Flow Acceleration .........................................................69

3.3.6 Newtonian Fluid, No-Slip, Boundary Conditions and Entry

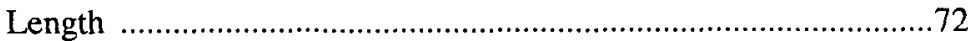

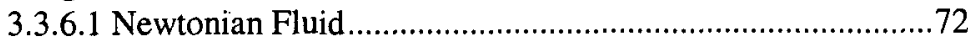

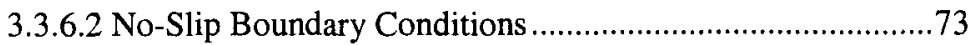

3.3.6.3 Laminar and Turbulent Flow...............................................73

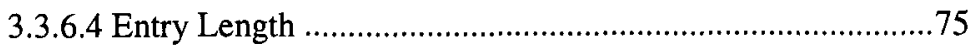

4. Hemodynamics of Large Arteries

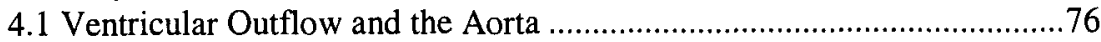

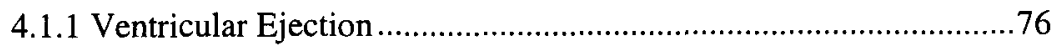

4.1.2 Cardiac Muscle Contraction and Force-Length-Velocity

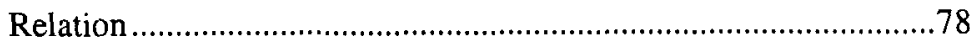

4.1.3 The Pressure-Volume Curve and Contractility of the Heart ............81

4.1.4 Ejection Fraction, Cardiac Performance, Preload and Afterload .....82

4.1.5 Coupling of the Ventricle and the Arterial System ..........................83

4.1.6 Dynamic of Heart-Arterial System Interactions................................87

4.2 Pressure-Flow Relations and Vascular Impedance ..................................89

4.2.1 Pressure and Flow Waveforms in Large and Small Arteries ...........89

4.2.2 Vascular Impedance to Blood Flow ...............................................94

4.3 Wave Propagation Phenomena ......................................................99

4.3.1 The Propagation Constant ..........................................................99

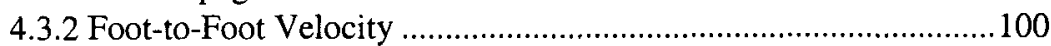

4.3.3 Apparent Propagation Constant and Transfer Function ..................103

4.3.4 Determination of the Propagation Constant ...................................107 
4.4 Wave Reflection Phenomena.

4.4.1 Influence of Wave Reflections on Pressure and

Flow Waveforms.

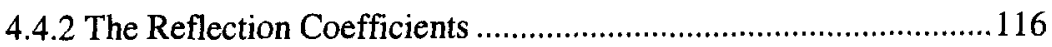

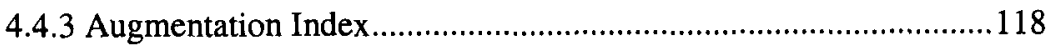

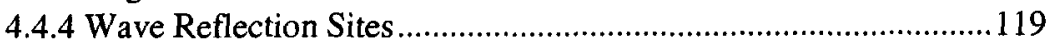

4.5 Modeling Aspects of the Arterial System ............................................. 120

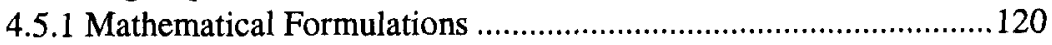

4.5.2 Linear Theories of Oscillatory Blood Flow in Arteries .................124

4.5.3 The Lumped Model of the Arterial System: The Windkessel........130

4.5.4 Nonlinear Aspects and Pressure-Dependent Arterial

Compliance

5. Vascular Branching

5.1 Branching Geometry

5.1.1 Complexity of Vascular Branching.............................................. 142

5.1.2 Nonuniform Branching and 3-D Branching Structure ...................144

5.1.3 Space-Filling Properties and Modeling ...........................................146

5.2 Fluid Mechanics of Vascular Branching ...............................................148

5.2.1 Branching Geometry and Fluid Dynamic Considerations .............148

5.2.2 Fluid Mechanics Associated with Atherosclerosis and Stenosis....154

5.3 Pulse Transmission Characteristics at Vascular Branching ....................157

5.3.1 Impedance Matching and Wave Reflections..................................157

5.3.2 Area Ratio Concept ......................................................................160

5.3.3 Minimum Local Reflections at Vascular Branching Junctions......164

5.4 Optimization Aspects Applicable to Vascular Branching........................166

5.4.1 Optimizing Vessel Radius and the Cube Law...............................166

5.4.2 Optimizing Branching Radii and Angles ........................................170

6. The Venous System

6.1 The Reservoir Properties and Venous Return .......................................172

6.1.1 Venous Compliance and Reservoir Characteristics .......................172

6.1.2 Structural Properties of Veins ......................................................174

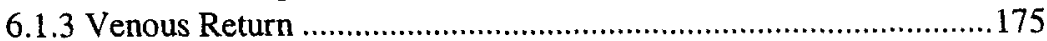

6.2 Pressure and Flow Waveforms in Vein...............................................176

6.2.1 The Normal Pressure and Flow Waveforms in Veins .....................176

6.2.2 Respiration Effects on Venous Pressure and Flow Waveforms .....178

6.2.3 Abnormal Venous Pressure and Flow Waveforms .........................180

6.3 Modeling and Collapsible Vessel Properties .........................................182

6.3.1 Steady Flow in Collapsible Tubes..................................................182

6.3.2 Flow Limitation and Model Experiments .......................................184

6.3.3 Pulse Wave Transmission Characteristics in Veins ........................188 
7. The Microcirculation

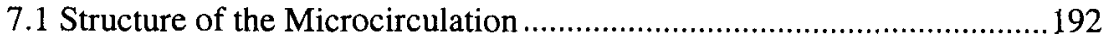

7.1.1 Functional Organization of the Microvasculature.........................192

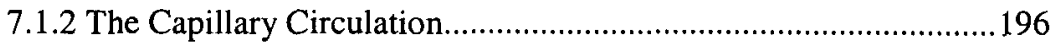

7.2 Pressure-Flow Relation and Microcirculatory Mechanics .....................200

7.2.1 Flow-Related Mechanical Characteristics of the

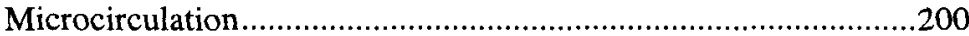

7.2.2 Some Pressure-Related Mechanical Characteristics .....................202

7.3 Pulse Transmission and Modeling Aspects..........................................206

7.3.1 Pressure and Flow Waveforms in Arterioles and Capillaries.........206

7.3.2 Pulse Transmission Characteristics in the Microcirculation ..........208

7.3.3 Modeling Aspects of the Microcirculation....................................210

8. Hemodynamic Measurements and Dynamics of the Assisted Circulation 8.1 Pressure, Flow and Dimension Measurements .....................................214

8.1.1 Invasive Blood Pressure Measurements........................................214

8.1.1.1 The Needle-Pressure Transducer System.........................214

8.1.1.2 The Catheter-Pressure Transducer Systems .......................217

8.1.2 Noninvasive Blood Pressure Measurements ..................................222

8.1.2.1 Auscultatory Measurement of Blood Pressure ...................222

8.1.2.2 Blood Pressure Measurement with the Oscillometric

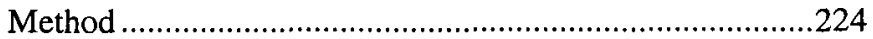

8.1.2.3 Noninvasive Blood Pressure Monitoring with

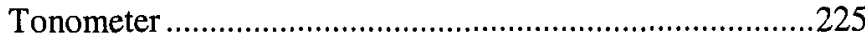

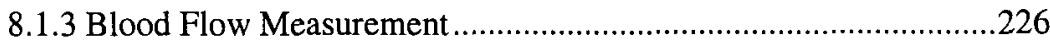

8.1.3.1 Electromagnetic Flowmeter ..........................................226

8.1.3.2 Ultrasound Doppler Velocimeters....................................227

8.1.3.3 Indicator Dilution Methods and Thermodilution ...............2229

8.1.4 Measurement of Vascular Dimensions .........................................2.233

8.2 The Assisted Circulation and the Intra-Aortic Balloon Pump..................234

8.2.1 Mechanical Assist Devices and the Assisted Circulation ..............234

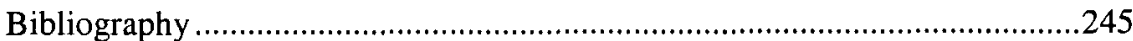

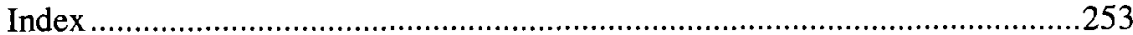

